\title{
Driving-Related Adverse Events in the Elderly Men: A Population-Based Prospective Cohort Study
}

\author{
Jae Sung Kim¹, Jong Bin Bae', Kyuhee Han¹, Jong Woo Hong1, Ji Hyun Han', Tae Hui Kim²,

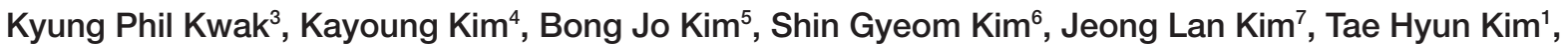 \\ Seok Woo Moon ${ }^{8}$, Jae Young Park ${ }^{1}$, Joon Hyuk Park ${ }^{9}$, Seonjeong Byun ${ }^{10,11}$, Seung Wan Suh'², \\ Ji Young Seo ${ }^{13}$, Yoonseop So ${ }^{1}$, Seung-Ho Ryu ${ }^{14}$, Jong Chul Youn ${ }^{15}$, Kyoung Hwan Lee ${ }^{16}$, \\ Dong Young Lee ${ }^{11,17}$, Dong-Woo Lee ${ }^{18}$, Seok Bum Lee ${ }^{19}$, Jung Jae Lee ${ }^{19}$, Ju Ri Lee', \\ Hyeon Jeong ${ }^{1}$, Hyun-Ghang Jeong ${ }^{20}$, Jin Hyeong Jhoo ${ }^{21}$, Ji Won Han ${ }^{1}$, and Ki Woong Kim ${ }^{1,11,22 凶}$ \\ ${ }^{1}$ Department of Neuropsychiatry, Seoul National University Bundang Hospital, Seongnam, Republic of Korea \\ ${ }^{2}$ Department of Psychiatry, Yonsei University Wonju Severance Christian Hospital, Wonju, Republic of Korea \\ ${ }^{3}$ Department of Psychiatry, Dongguk University Gyeongju Hospital, Gyeongju, Republic of Korea \\ ${ }^{4}$ Department of Psychiatry, National Center for Mental Health, Seoul, Republic of Korea \\ ${ }^{5}$ Department of Psychiatry, Gyeongsang National University College of Medicine, Jinju, Republic of Korea \\ ${ }^{6}$ Department of Neuropsychiatry, Soonchunhyang University Bucheon Hospital, Bucheon, Republic of Korea \\ ${ }^{7}$ Department of Psychiatry, School of Medicine, Chungnam National University, Daejeon, Republic of Korea \\ ${ }^{8}$ Department of Psychiatry, School of Medicine, Konkuk University, Konkuk University Chungju Hospital, Chungju, Republic of Korea \\ ${ }^{9}$ Department of Neuropsychiatry, Jeju National University Hospital, Jeju, Republic of Korea \\ ${ }^{10}$ Department of Neuropsychiatry, National Medical Center, Seoul, Republic of Korea \\ ${ }^{11}$ Department of Psychiatry, Seoul National University College of Medicine, Seoul, Republic of Korea \\ ${ }^{12}$ Department of Psychiatry, Kangdong Sacred Heart Hospital, Hallym University College of Medicine, Seoul, Republic of Korea \\ ${ }^{13}$ Department of Psychiatry, Gyeongsang National University Changwon Hospital, Changwon, Republic of Korea \\ ${ }^{14}$ Department of Psychiatry, School of Medicine, Konkuk University, Konkuk University Medical Center, Seoul, Republic of Korea \\ ${ }^{15}$ Department of Neuropsychiatry, Kyunggi Provincial Hospital for the Elderly, Yongin, Republic of Korea \\ ${ }^{16}$ Department of Psychiatry, Bongseng Memorial Hospital, Busan, Republic of Korea \\ ${ }^{17}$ Department of Neuropsychiatry, Seoul National University Hospital, Seoul, Republic of Korea \\ ${ }^{18}$ Department of Neuropsychiatry, Inje University Sanggye Paik Hospital, Seoul, Republic of Korea \\ ${ }^{19}$ Department of Psychiatry, Dankook University Hospital, Cheonan, Republic of Korea \\ ${ }^{20}$ Department of Psychiatry, Korea University Guro Hospital, Korea University College of Medicine, Seoul, Republic of Korea \\ ${ }^{21}$ Department of Psychiatry, Kangwon National University School of Medicine, Chuncheon, Republic of Korea \\ ${ }^{22}$ Department of Brain and Cognitive Science, Seoul National University College of Natural Sciences, Seoul, Republic of Korea
}

Objective This study estimated the incidence of driving-related adverse events and examined the association of cognitive function with the risk of future driving-related adverse events in the elderly Korean male population.

Methods We analyzed 1,172 male drivers aged 60 years or older in the Korean Longitudinal Study on Cognitive Aging and Dementia (KLOSCAD). Using the data from Korean National Police Agency, we classified the participants into three groups: safe driving (drove for 2 years after baseline without a traffic accident or repeated violations), driving cessation (stopped driving), and risky driving (one or more traffic accidents or repeated violations). We estimated the incidences of driving cessation and risky driving, and examined the effect of cognitive function on their risks.

Results The incidence of driving cessation and risky driving in the Korean male drivers aged 60 years or older was 19.3 and 69.9 per 1,000 person-years respectively and increased in the late 80s. Drivers with better baseline Word List Memory Test scores showed less risky driving $(\mathrm{OR}=0.94, \mathrm{p}=0.039)$.

Conclusion Driving-related adverse events increased in late $80 \mathrm{~s}$, and better memory function was protective against these events.

Psychiatry Investig 2020;17(8):744-750

Key Words Driving, Incidence, Accident, Violation, Memory.

\footnotetext{
Received: September 3, 2019 Revised: January 12, 2020 Accepted: March 18, 2020

$\triangle$ Correspondence: Ki Woong Kim, MD, PhD

Department of Neuropsychiatry, Seoul National University College of Medicine, Seoul National University Bundang Hospital, 82 Gumi-ro 173 beon-gil, Bundang-gu, Seongnam 13620, Republic of Korea

Tel: +82-31-787-7432, Fax: +82-31-787-4058, E-mail: kwkimmd@snu.ac.kr

(c) This is an Open Access article distributed under the terms of the Creative Commons Attribution Non-Commercial License (https://creativecommons.org/licenses/by-nc/4.0) which permits unrestricted non-commercial use, distribution, and reproduction in any medium, provided the original work is properly cited.
} 


\section{INTRODUCTION}

In modern society, driving allows self-determination of mobility and accessibility to broader community environment, which are important for both the physical and mental health of older individuals. Driving reduction or cessation may lead to depression ${ }^{1,2}$ and deterioration of overall physical health, and even increased mortality. ${ }^{2,3}$ However, older drivers may pose a threat to general transportation safety, as they show an increasing risk of driving-related adverse events, ${ }^{4}$ especially fatal accident involvements per mile., ${ }^{5,6}$ To maximize the benefits to old drivers of driving and to minimize their drivingrelated adverse events, guidelines regulating the driving of old individuals should be properly and timely prepared. In many countries, driving licenses are regulated in accordance with the drivers' age or cognitive status, including a diagnosis of dementia. $^{7}$

Physical and cognitive abilities required for driving greatly differ between individuals. ${ }^{8}$ Previous studies applied various cognitive tests such as the MMSE, ${ }^{9}$ MoCA,,${ }^{10}$ Trail Making Test, ${ }^{11,12}$ and Stroop test ${ }^{12}$ in order to evaluate the cognitive fitness of old individuals for driving. However, their results were inconsistent. ${ }^{13,14}$ Moreover, the impact of memory decline on driving has been barely studied in the elderly despite the fact that memory decline is one of the representative symptoms in the cognitively impaired older individuals. In addition, their study samples were relatively small, ranging from 50 to 400 , and mostly consisted of cognitively impaired elderly. Furthermore, most studies evaluated the results of a virtual reality driving test, test vehicle driving test, or on-road driving test instead of actual driving-related adverse events. Due to these limitations, the results of previous research show limitations in generalizability.

This study aimed to estimate the incidence of driving-related adverse events and to examine the association of cognitive function with the risk of future driving-related adverse events in a prospective, population-based elderly cohort study.

\section{METHODS}

\section{Participants}

This study was conducted as a part of the Korean Longitudinal Study on Cognitive Aging and Dementia (KLOSCAD) ${ }^{15}$ The KLOSCAD is a nationwide, population-based, prospective cohort study of 6,818 community-dwelling Koreans aged 60 years or older who were randomly sampled from 30 villages and towns across South Korea using residential rosters. The baseline evaluation was conducted from November 2010 to October 2012, and follow-up evaluations are conducted every two years. Among the 6,818 participants, our study in- cluded 1,172 men who were driving at the time of baseline evaluation and completed the first 2-year follow-up evaluation (Table 1).

The study protocol was approved by the Institutional Review Board of the Seoul National University Bundang Hospital (B-0912/089-010). In all cases, a written statement of informed consent was obtained from either the participants themselves or their legal guardians.

\section{Assessments}

In both baseline and follow-up evaluations, geriatric psychiatrists administered standardized clinical interviews, neurological and physical examinations, and laboratory tests using the Korean version of the Consortium to Establish a Registry for Alzheimer's Disease (CERAD-K) Clinical Assessment Battery, ${ }^{16}$ the Korean version of the Mini International Neuropsychiatric Interview (MINI), ${ }^{17}$ and the Tinetti Performance Oriented Mobility Assessment (POMA) ${ }^{18}$ Research neuropsychologists or trained nurses administered the CERAD-K Neuropsychological Assessment Battery (CERAD-K-N). ${ }^{16,19}$ A panel of four research geriatric psychiatrists diagnosed dementia according to the DSM-IV-TR diagnostic criteria ${ }^{20}$ and MCI according to the consensus criteria proposed by the International Working Group on MCI. ${ }^{21}$ We defined the participants with dementia or MCI as the cognitive disorder group (CD+).

We assessed information on the driving, including driving status, of study participants at both the baseline and follow-up evaluation using the Driving Risk Questionnaire ${ }^{22}$ and an additional survey. ${ }^{15}$ We obtained the time, place, and type of all traffic accidents and violations in which they were recorded as involved between January 2010 and October 2014 from the Korean National Police Agency (KNPA) in October, 2014.

\section{Statistical analysis}

We compared the baseline characteristics between groups using analysis of variance (ANOVA) or Student's t-test for continuous variables and chi square test for categorical variables.

We classified the driving behaviors of the participants into three groups: The safe driving group, who continued driving for more than 2 years after the baseline evaluation without a traffic accident or repeated violations; the driving cessation group, who stopped driving within 2 years from the baseline evaluation regardless of traffic accidents or repeated violations; and the risky driving group, who had one or more traffic accidents or repeated violations within 2 years after the baseline evaluation. We estimated age-adjusted incidence rates of traffic accidents, repeated violations, risky driving, and driving cessation in Korean male drivers aged 60 years or older with a direct standardization method using the 2010 National Census data of South Korea. To estimate age-adjusted incidence 
Table 1. Baseline characteristics of the participants

\begin{tabular}{|c|c|c|c|c|}
\hline & \multirow{2}{*}{$\begin{array}{c}\text { All } \\
(\mathrm{N}=1,172)\end{array}$} & \multicolumn{3}{|c|}{ Cognitive disorder } \\
\hline & & No $(N=842)$ & Yes $(\mathrm{N}=330)$ & $\mathrm{p}^{*}$ \\
\hline Age (years, mean $\pm S D$ ) & $67.05 \pm 5.10$ & $66.65 \pm 4.90$ & $68.09 \pm 5.46$ & 0.003 \\
\hline Education (years, mean \pm SD) & $12.08 \pm 4.48$ & $12.08 \pm 4.48$ & $12.09 \pm 4.50$ & 0.686 \\
\hline POMA (points, mean $\pm S D$ ) & $26.87 \pm 5.24$ & $26.85 \pm 5.39$ & $26.94 \pm 4.86$ & 0.399 \\
\hline GDS (points, mean \pm SD) & $7.78 \pm 5.82$ & $7.08 \pm 5.45$ & $9.58 \pm 6.35$ & $<0.001$ \\
\hline Driving duration (days, mean \pm SD) & $10562.69 \pm 3592.11$ & $10603.23 \pm 3476.47$ & $10459.26 \pm 3875.18$ & 0.055 \\
\hline Verbal Fluency (points, mean \pm SD) & $16.13 \pm 4.60$ & $16.40 \pm 4.44$ & $15.46 \pm 4.92$ & 0.027 \\
\hline Boston Naming Test (points, mean \pm SD) & $13.68 \pm 1.50$ & $13.79 \pm 1.46$ & $13.40 \pm 1.57$ & 0.002 \\
\hline MMSE (points, mean $\pm S D$ ) & $27.45 \pm 2.27$ & $27.68 \pm 2.22$ & $26.89 \pm 2.32$ & 0.075 \\
\hline WLMT (points, mean $\pm S D$ ) & $16.53 \pm 3.86$ & $17.08 \pm 3.65$ & $15.11 \pm 4.01$ & 0.055 \\
\hline Constructional Praxis (points, mean \pm SD) & $10.22 \pm 1.29$ & $10.20 \pm 1.35$ & $10.27 \pm 1.14$ & 0.630 \\
\hline WLRT (points, mean \pm SD) & $5.29 \pm 1.92$ & $5.61 \pm 1.80$ & $4.46 \pm 1.98$ & 0.004 \\
\hline WLRcT (points, mean \pm SD) & $8.72 \pm 1.64$ & $9.00 \pm 1.30$ & $7.98 \pm 2.11$ & $<0.001$ \\
\hline Constructional Praxis Recall (points, mean \pm SD) & $7.24 \pm 2.74$ & $7.49 \pm 2.66$ & $6.60 \pm 2.84$ & 0.222 \\
\hline $\mathrm{DRQ}$ (points, mean $\pm \mathrm{SD}$ ) & $20.42 \pm 8.48$ & $19.98 \pm 8.40$ & $21.55 \pm 8.58$ & 0.835 \\
\hline
\end{tabular}

*student's t-test. SD: standard deviation, POMA: Tinetti Performance Oriented Mobility Assessment, GDS: Geriatric Depression Scale, MMSE: Mini Mental Status Examination, WLMT: Word List Memory Test, WLRT: Word List Recall Test, WLRcT: Word List Recognition Test, DRQ: Driving Risk Questionnaire

rates, we stratified the ages of the participants into six groups (60-64, 65-69, 70-74, 75-79, 80-84, and 85+).

To examine the association of baseline global cognition and memory with future risks of driving cessation and risky driving, we conducted multinomial logistic regression analyses that treated scores on the Mini Mental Status Examination (MMSE), Word List Memory Test (WLMT), Word List Recall Test (WLRT), and Word List Recognition Test (WLRcT) as independent variables and age, Geriatric Depression Score and duration of driving as covariates. The MMSE, WLMT, WLRT, and WLRcT are the subscales of the CERAD-K-N. To examine the association of cognitive disorder with the risks of future driving cessation and risky driving, we conducted multinomial logistic regression analysis that employed the cognitively normal drivers (CD-) as the referent group. Due to the limited number of dementia patients, we additionally compared the risks of future driving cessation and risky driving of $\mathrm{MCI}$ group separately with those of the $\mathrm{CD}$ - group.

We performed all statistical analyses using the Statistical Package for the Social Sciences (SPSS) for Windows, Version 20.0 (IBM Corp., Armonk, NY, USA).

\section{RESULTS}

As shown in Figure 1, the incidence of risky driving soared in their late 80s. During the same period, 66 (32 in CD+ and 34 in CD-) stopped driving, but none of them had one or more traffic accidents or repeated violations. Among the 1,172 men

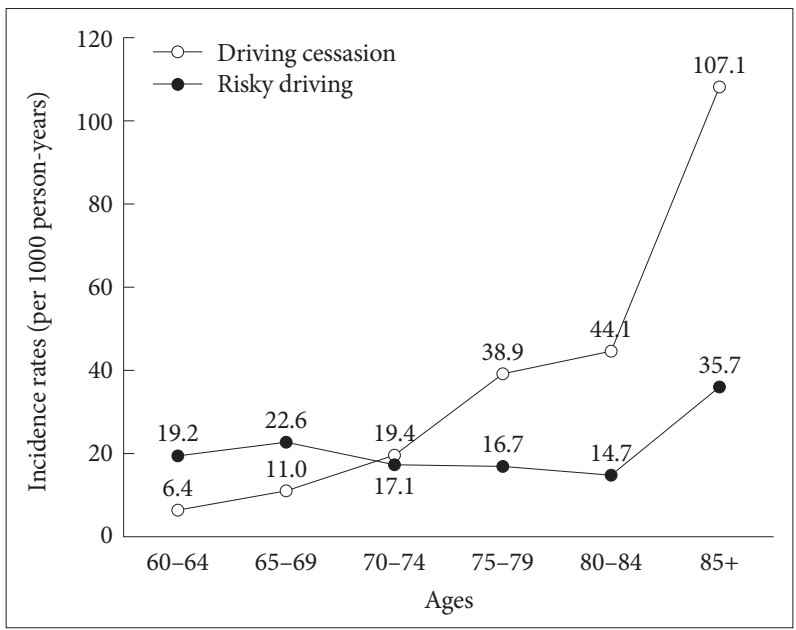

Figure 1. Age-specific incidence rates (per 1000 person-years) of driving cessation and risky driving.

who were driving at the baseline evaluation, 325 and 5 were diagnosed as having $\mathrm{MCI}$ and dementia, respectively. Among them, 80 (18 in CD+ and 62 in CD-) had traffic accidents, 119 (30 in $\mathrm{CD}+$ and 89 in $\mathrm{CD}$-) had repeated violations, and 157 (40 in CD+ and 117 in CD-) had one or more traffic accidents or repeated violations within 2 years after the baseline evaluation.

The age standardized incidence rates of risky driving and driving cessation in the Korean male drivers aged 60 years or older were estimated to be 69.9 per 1,000 persons per year (95\% CI $=59.5-80.2)$ and 19.3 per 1,000 persons per year (95\% $\mathrm{CI}=15.3-23.2)$, respectively. When we analyzed the traffic ac- 
cident and repeated violations in the risky driving, their incidence rates were estimated to be 38.7 per 1,000 persons per year (95\% CI=33.2-44.2) and 54.3 per 1,000 persons per year (95\% CI $=45.1-63.5)$ respectively. The participants scored higher on all four cognitive tests in the order of the safe, risky, and driving cessation groups (Table 2). The higher the baseline WLMT score, the lower the risk of risky driving ( $\mathrm{OR}=0.94$, 95\% CI=0.88-0.997). The higher baseline WLRT score meant the lower risk of risky driving $(\mathrm{OR}=0.88,95 \% \mathrm{CI}=0.78-1.001)$, although it was slightly statistically insignificant. When we analyzed the risk of MCI separately, the protective effect of higher WLMT score on the risk of risky driving was not changed. However, the protective effect of higher WLRT score on the risk risky driving further lost its statistical significance $(\mathrm{OR}=$ 0.89, 95\% CI=0.78-1.01).

The MMSE and WLRcT scores were not associated with the risks of driving cessation or risky driving (Table 3), which was the case when we analyzed the participants after excluding the 5 incident dementia patients at follow-up. Although the driving cessation group showed a higher prevalence of cognitive disorder than the safe driving group, the risky driving group showed a prevalence of cognitive disorder comparable to that of the safe driving group (Table 2).

As summarized in Table 4, the CD+ group showed a risk of driving cessation about two times higher than the $\mathrm{CD}$ - group ( $\mathrm{OR}=1.89,95 \% \mathrm{CI}=1.11-3.24)$, and a comparable risk of risky driving to the $\mathrm{CD}$ - group $(\mathrm{OR}=0.82,95 \% \mathrm{CI}=0.55-1.22)$. When we analyzed the risks of traffic accidents and repeated violations separately, the $\mathrm{CD}+$ group showed risks of repeated violations $(\mathrm{OR}=1.22,95 \% \mathrm{CI}=0.78-1.91)$ and traffic accidents $(\mathrm{OR}=$ $1.44,95 \% \mathrm{CI}=0.83-2.51)$ comparable to those of the CD- group.

\section{DISCUSSION}

The number of old drivers is steadily rising as the world's older population grows rapidly. As the ability to drive allows the older population self-determined mobility, driving is becoming more significant for the health and well-being of old people than ever before. ${ }^{2,8}$ In accordance with the increasing number of old drivers, the number and proportion of traffic accidents caused by old drivers have been on the rise. ${ }^{23}$ In South Korea, the number of traffic accidents caused by drivers aged 65 years or older increased from 12,623 cases in 2010 to 20,275 cases in 2014 and 26,713 cases in 2017 . In the same period, the number of drivers older than 65 increased from $1,826,718$ in 2014 to $2,729,392$ in 2017 . The national proportion of traffic accidents caused by old drivers also increased from $5.6 \%$ in 2010 to $9.0 \%$ in 2014 and $12.3 \%$ in $2017 .^{24}$

However, in the current study, the incidence of driving-related adverse events decreased until participants' early 80 s and then started to increase in their late $80 \mathrm{~s}$. The decrease in the incidence until the early 80 s may be attributable to decreases in driving mileage ${ }^{25}$ and increases in driving cessation as drivers age. ${ }^{26}$ Although there are no statistics on the driving mileages of old drivers stratified by age in Korea, the driving mileages of drivers aged 50 years old or older were found to be more than $10 \%$ less than in the drivers below 50 years of age. ${ }^{27}$ In the United States, driving mileages start to decrease from 65 years of age $e^{28}$ and the average daily driving mileage in drivers aged 75 years old or over was about half that of the drivers aged $65-74$ years. ${ }^{26}$ When driving distance is taken into account, the incidence of car crashes increases with the advancing age of drivers in the United States: 241 per 100 mil-

Table 2. Comparison of the baseline characteristics between the safe driving group, driving cessation group and risky driving group

\begin{tabular}{|c|c|c|c|c|c|c|}
\hline & \multirow{2}{*}{$\begin{array}{l}\text { Safe driving }{ }^{\mathrm{a}} \\
\qquad(\mathrm{N}=951)\end{array}$} & \multirow{2}{*}{$\begin{array}{l}\text { Driving cessation } \\
\qquad(\mathrm{N}=66)\end{array}$} & \multirow{2}{*}{$\begin{array}{l}\text { Risky driving }^{c} \\
\qquad(\mathrm{~N}=155)\end{array}$} & \multicolumn{3}{|c|}{ Statistics* } \\
\hline & & & & F or $\chi^{2}$ & $\mathrm{p}$ & post-hoc \\
\hline Age (years, mean $\pm S D$ ) & $66.79 \pm 4.88$ & $71.18 \pm 6.19$ & $66.92 \pm 5.24$ & 23.83 & $<0.001$ & $\mathrm{~b}>\mathrm{a}, \mathrm{c}$ \\
\hline Education (years, mean $\pm S D$ ) & $12.32 \pm 4.37$ & $10.92 \pm 5.32$ & $11.10 \pm 4.58$ & 7.32 & 0.001 & $a>b, c$ \\
\hline POMA (points, mean $\pm S D$ ) & $26.97 \pm 5.02$ & $26.08 \pm 6.71$ & $26.61 \pm 5.87$ & 1.12 & 0.327 & - \\
\hline GDS (points, mean \pm SD) & $7.64 \pm 5.80$ & $9.03 \pm 6.35$ & $8.17 \pm 5.70$ & 2.18 & 0.114 & - \\
\hline Driving duration (days, mean $\pm \mathrm{SD}$ ) & $10640.41 \pm 3490.12$ & $9038.14 \pm 4789.15$ & $10735.03 \pm 3496.99$ & 6.40 & 0.002 & $a, c>b$ \\
\hline MMSE (points, mean $\pm S D$ ) & $27.55 \pm 2.14$ & $26.71 \pm 1.98$ & $27.13 \pm 3.01$ & 6.19 & 0.002 & $\mathrm{a}>\mathrm{c}>\mathrm{b}$ \\
\hline WLMT (points, mean $\pm S D$ ) & $16.86 \pm 3.72$ & $13.94 \pm 3.71$ & $15.55 \pm 4.12$ & 24.45 & $<0.001$ & $a>c>b$ \\
\hline WLRT (points, mean $\pm S D$ ) & $5.45 \pm 1.86$ & $4.15 \pm 2.06$ & $4.79 \pm 1.99$ & 20.64 & $<0.001$ & $a>c>b$ \\
\hline WLRcT(points, mean $\pm S D$ ) & $8.81 \pm 1.54$ & $7.91 \pm 2.15$ & $8.49 \pm 1.86$ & 11.19 & $<0.001$ & $a>c>b$ \\
\hline DRQ (points, mean \pm SD) & $20.53 \pm 8.20$ & $20.86 \pm 10.97$ & $19.60 \pm 8.97$ & 0.89 & 0.411 & - \\
\hline Cognitive disorder $(\%)^{\dagger}$ & 27.3 & 48.5 & 24.5 & 14.81 & 0.001 & $\mathrm{~b}>\mathrm{a}, \mathrm{c}$ \\
\hline
\end{tabular}

*analysis of variance or chi square test with Bonferroni post-hoc comparisons, ${ }^{\dagger}$ dementia or mild cognitive impairment. SD: standard deviation, POMA: Tinetti Performance Oriented Mobility Assessment, GDS: Geriatric Depression Scale, MMSE: Mini Mental Status Examination, WLMT: Word List Memory Test, WLRT: Word List Recall Test, WLRcT: Word List Recognition Test, DRQ: Driving Risk Questionnaire 
Table 3. Effects of baseline global cognitive function and memory function on the future risks of driving cessation and risky driving in old male drivers

\begin{tabular}{lcc}
\hline & $\begin{array}{c}\text { Odds ratio } \\
(95 \% \text { CD })^{*}\end{array}$ & $\mathrm{p}^{*}$ \\
\hline All participants & & \\
Driving cessation ${ }^{\dagger}$ & & \\
MMSE (points) & $0.99(0.89-1.10)$ & 0.837 \\
Word List Memory Test (points) & $0.93(0.85-1.02)$ & 0.129 \\
Word List Recall Test (points) & $0.87(0.71-1.05)$ & 0.152 \\
Word List Recognition Test (points) & $0.998(0.85-1.17)$ & 0.985 \\
Risky driving ${ }^{\ddagger}$ & & \\
MMSE (points) & $0.98(0.91-1.05)$ & 0.584 \\
Word List Memory Test (points) & $0.94(0.88-0.997)$ & 0.039 \\
Word List Recall Test (points) & $0.88(0.78-1.001)$ & 0.051 \\
Word List Recognition Test (points) & $1.04(0.91-1.17)$ & 0.589 \\
MCI patients & & \\
Driving cessation ${ }^{\dagger}$ & & \\
MMSE (points) & & \\
Word List Memory Test (points) & $0.93(0.85-1.02)$ & 0.141 \\
Word List Recall Test (points) & $0.86(0.71-1.05)$ & 0.134 \\
Word List Recognition Test (points) & $0.99(0.84-1.17)$ & 0.921 \\
Risky driving ${ }^{\ddagger}$ & & \\
MMSE (points) & $0.97(0.90-1.05)$ & 0.439 \\
Word List Memory Test (points) & $0.94(0.88-0.995)$ & 0.035 \\
Word List Recall Test (points) & $0.89(0.78-1.01)$ & 0.064 \\
Word List Recognition Test (points) & $1.03(0.91-1.16)$ & 0.700 \\
\hline
\end{tabular}

*multinomial logistic regression analysis adjusting age, Geriatric Depression Scale scores and duration of driving as covariates $(-2$ $\log$ likelihood $=1404.31, \mathrm{df}=14, \mathrm{p}<0.001$ for all participants $(-2 \log$ likelihood=1397.29, df=14, $\mathrm{p}<0.001$ for MCI patients), ${ }^{\dagger}$ stopped driving within 2 years from the baseline evaluation without a traffic accident or repeated violations, thad one or more traffic accidents or repeated violations within 2 years from the baseline evaluation. MCI: mild cognitive impairment

lion miles driven in 60-69-year-old drivers, 301 per 100 million miles driven in ages 70-79, and 432 crashes per 100 million miles driven in drivers older than $80 .{ }^{26}$ In addition, the age-associated increase in the risk of driving-related adverse events may be even larger when the age-associated increase of driving cessation is taken into account.

A particularly notable finding of the current study is that the risk of driving-related adverse events increased in participants' late 80 s despite the fact that the driving distance in this age group may be shorter than that in the elderly aged 84 years or younger. This study found that about 1 out of 9 male drivers aged 85 years or older may be involved in one or more traffic accidents or repeated violations every year. In 2018, the number of driving license holders aged 85 years or older was 41,476 in Korea. ${ }^{24}$ The Korean government has recently introduced
Table 4. Effects of cognitive impairment on the future risks of driving cessation and risky driving in old male drivers

\begin{tabular}{lcc}
\hline & Odds ratio (95\% CD)* & $\mathrm{p}^{*}$ \\
\hline Cognitive disorder & & \\
Driving cessation $^{\dagger}$ & $1.89(1.11-3.24)$ & 0.020 \\
Risky driving $^{\ddagger}$ & $0.82(0.55-1.22)$ & 0.324 \\
$\begin{array}{l}\text { Mild cognitive impairment } \\
\text { Driving cessation }\end{array}$ & $1.84(1.07-3.17)$ & 0.027 \\
Risky driving $^{\dagger}$ & $0.83(0.55-1.23)$ & 0.348 \\
\hline
\end{tabular}

*multinomial logistic regression analyses employing the old male drivers with normal cognition as reference group adjusting age, Geriatric Depression Scale scores and duration of driving as covariates $(-2 \log$ likelihood $=1055.88, \mathrm{df}=6, \mathrm{p}<0.001$ for Cognitive disorder, $-2 \log$ likelihood=1394.52, $\mathrm{df}=8, \mathrm{p}<0.001$ for Mild cognitive impairment), ${ }^{\dagger}$ stopped driving within 2 years from the baseline evaluation without a traffic accident or repeated violations, thad one or more traffic accidents or repeated violations within 2 years after the baseline evaluation

several policy measures to encourage elderly people to stop driving. From 2019, drivers older than 75 years are obliged to renew their driver's license and take an aptitude test every three years. However, considering the soaring incidence rate of drivers older than 85 in our study, an additional management system is required for the drivers aged 85 years or older, such as shortening the renewal cycle of driving licenses to one year and a mandatory aptitude test for drivers involved in a traffic accident or violation.

In the current study, the future risk of driving-related adverse events was associated with the memory function of the drivers but not with their age per se. These results held when we computed cognitive function as the presence of cognitive disorders instead of using cognitive test scores, and are in line with previous studies showing that age-related functional decline, rather than aging itself, increases the risk of driving-related adverse events. ${ }^{8,29}$ Previous studies have shown that no single domain of cognitive function was sufficient to predict the driving ability of individuals, emphasizing the importance of developing a composite battery that includes multiple cognitive domains. ${ }^{30}$ However, a comprehensive neuropsychological battery that can evaluate multiple cognitive domains may lack practicality as a screening instrument to be administered to every elderly driver because it is expensive, usually takes longer than an hour, and needs a well-trained psychologist to administer. In addition, this study found that the MMSE, a short screening test for measuring overall cognitive function, may not properly predict the future risk of driving-related adverse events. This is in line with previous studies showing that the MMSE was insensitive to the risk of unsafe driving ${ }^{31}$ and that the items of the MMSE were relatively less associated with driving ability. ${ }^{14,32}$

Currently, there are no specific guidelines regarding aptitude tests for the renewal of driver's license in older drivers in 
Korea. Medical examinations instead of standardized cognitive function tests are performed in the case of license renewal. ${ }^{7}$ The Korea Road Traffic Authority provides cognitive function tests for the purpose of education of older drivers, but these include only evaluations of attention and visuospatial function, not memory function tests. Since performance on the WLMT, which evaluate learning ability and working memory, was associated with the risk of risky driving in the present study, screening instruments to verify driving fitness may need to include more questions on memory functions. The goal directedness of working memory allows the driver to keep various information in mind in order to be able to manipulate it, thereby minimizing the effect of distracting situations, which is crucial in maintaining driving ability. ${ }^{33}$ For aptitude tests under development to measure the driving safety of old drivers, we recommend based on our study findings that evaluations of working memory and short term memory function be included.

Although not statistically significant, it is noteworthy that the risk of risky driving tended to be lower in $\mathrm{CD}+$ group $(\mathrm{OR}=$ $0.82,95 \% \mathrm{CI}=0.55-1.22$ ). However, such tendency should not be literally understood as lower risk in CD+ group. Rather, considering about twice higher risk of driving cessation in $\mathrm{CD}+$ group, more cognitively unfit drivers might have ceased driving, therefore leaving relatively larger number of risky drivers in the CD- group.

This study has several limitations. First, this study included only male drivers. This is mainly due to relative scarcity of female drivers among elderly Koreans. Women are known to be more prudent than men in driving-related behaviors, including determining whether or not to continue driving. ${ }^{34}$ Second, the duration of the follow-up may not be sufficient to capture the effect of cognition on driving behaviors because elderly drivers would be able to buffer decreased driving abilities due to cognitive decline for several years via adaptive behaviors in their familiar driving environments. Third, we did not consider the causes of cognitive disorders. The profile of cognitive disorders and accompanied non-cognitive symptoms may differ depending on the causes of cognitive disorders. For instance, Lewy body disease shows greater impairment of visuospatial and motor abilities than $\mathrm{AD} .^{35}$

In conclusion, driving-related adverse events increased in drivers' late 80 s, and better memory function was protective against the risk of driving-related adverse events.

\section{Acknowledgments}

This work was Supported by grant no 02-2016-039 from the SNUBH Research Fund.

\section{Conflicts of Interest}

The authors have no potential conflicts of interest to disclose.

\section{Author Contributions}

Conceptualization: Ki Woong Kim. Data curation: Jae Sung Kim, Ji Won Han. Formal analysis: Jae Sung Kim, Ki Woong Kim. Funding acquisition: Ki Woong Kim. Investigation: all authors. Methodology: all authors. Project administration: Ji Won Han, Ki Woong Kim. Resources: all authors. Software: Jae Sung Kim, Ki Woong Kim. Supervision: Ji Won Han, Ki Woong Kim. Validation: Ji Won Han, Ki Woong Kim. Visualization: Jae Sung Kim, Ki Woong Kim. Writing-original draft: Jae Sung Kim, Ki Woong Kim. Writing-review \& editing: all authors.

\section{ORCID iDs}

$\begin{array}{ll}\text { Jae Sung Kim } & \text { https://orcid.org/0000-0002-6306-0604 } \\ \text { Jong Bin Bae } & \text { https://orcid.org/0000-0002-3913-1011 } \\ \text { Kyuhee Han } & \text { https://orcid.org/0000-0003-1634-1523 } \\ \text { Jong Woo Hong } & \text { https://orcid.org/0000-0002-8906-3352 } \\ \text { Ji Hyun Han } & \text { https://orcid.org/0000-0001-8842-5553 } \\ \text { Tae Hui Kim } & \text { https://orcid.org/0000-0003-0133-5227 } \\ \text { Kyung Phil Kwak } & \text { https://orcid.org/0000-0003-4555-0105 } \\ \text { Kayoung Kim } & \text { https://orcid.org/0000-0002-8847-9620 } \\ \text { Bong Jo Kim } & \text { https://orcid.org/0000-0003-2419-7306 } \\ \text { Shin Gyeom Kim } & \text { https://orcid.org/0000-0001-8196-655X } \\ \text { Jeong Lan Kim } & \text { https://orcid.org/0000-0002-6554-4637 } \\ \text { Tae Hyun Kim } & \text { https://orcid.org/0000-0002-6393-8026 } \\ \text { Seok Woo Moon } & \text { https://orcid.org/0000-0002-1074-8122 } \\ \text { Jae Young Park } & \text { https://orcid.org/0000-0001-7008-2011 } \\ \text { Joon Hyuk Park } & \text { https://orcid.org/0000-0002-0396-5284 } \\ \text { Seonjeong Byun } & \text { https://orcid.org/0000-0003-0864-9835 } \\ \text { Seung Wan Suh } & \text { https://orcid.org/0000-0003-3190-0354 } \\ \text { Ji Young Seo } & \text { https://orcid.org/0000-0002-7329-8296 } \\ \text { Yoonseop So } & \text { https://orcid.org/0000-0003-4142-9420 } \\ \text { Seung-Ho Ryu } & \text { https://orcid.org/0000-0001-8057-8723 } \\ \text { Jong Chul Youn } & \text { https://orcid.org/0000-0002-2904-8951 } \\ \text { Kyoung Hwan Lee } & \text { https://orcid.org/0000-0002-7246-1653 } \\ \text { Dong Young Lee } & \text { https://orcid.org/0000-0001-8976-8320 } \\ \text { Dong-Woo Lee } & \text { https://orcid.org/0000-0002-6383-1974 } \\ \text { Seok Bum Lee } & \text { https://orcid.org/0000-0002-5481-4697 } \\ \text { Jung Jae Lee } & \text { https://orcid.org/0000-0002-0828-3557 } \\ \text { Ju Ri Lee } & \text { https://orcid.org/0000-0001-7631-4004 } \\ \text { Hyeon Jeong } & \text { https://orcid.org/0000-0002-5811-1104 } \\ \text { Hyun-Ghang Jeong } & \text { https://orcid.org/0000-0002-0318-5069 } \\ \text { Jin Hyeong Jhoo } & \text { https://orcid.org/0000-0002-8147-5782 } \\ \text { Ji Won Han } & \text { https://orcid.org/0000-0003-2418-4257 } \\ \text { Ki Woong Kim } & \text { https://orcid.org/0000-0002-1103-3858 }\end{array}$

\section{REFERENCES}

1. Ragland DR, Satariano WA, MacLeod KE. Driving cessation and increased depressive symptoms. J Gerontol A Biol Sci Med Sci 2005;60: 399-403.

2. Chihuri S, Mielenz TJ, DiMaggio CJ, Betz ME, DiGuiseppi C, Jones VC, et al. Driving cessation and health outcomes in older adults. J Am Geriatr Soc 2016;64:332-341.

3. O'Connor ML, Edwards JD, Waters MP, Hudak EM, Vald?s EG. Mediators of the association between driving cessation and mortality among older adults. J Aging Health 2013;25(8_suppl):249S-269S.

4. Braver ER, Trempel R. Are older drivers actually at higher risk of involvement in collisions resulting in deaths or non-fatal injuries among their passengers and other road users? Inj Prev 2004;10:27-32.

5. Li G, Braver ER, Chen LH. Fragility versus excessive crash involvement as determinants of high death rates per vehicle-mile of travel among older drivers. Accid Anal Prev 2003;35:227-235.

6. Tefft B. Rates of Motor Vehicle Crashes, Injuries and Deaths in Relation to Driver Age, United States, 2014-2015. Washington, DC: AAA Foundation for Traffic Safety; 2017. 
7. Kim YJ, An H, Kim B, Park YS, Kim KW. An international comparative study on driving regulations on people with dementia. J Alzheimers Dis 2017;56:1007-1014.

8. Karthaus M, Falkenstein M. Functional changes and driving performance in older drivers: assessment and interventions. Geriatrics (Basel) 2016;1. pii: E12.

9. Adler G, Kuskowski M. Driving cessation in older men with dementia. Alzheimer Dis Assoc Disord 2003;17:68-71.

10. Kwok JCW, Gélinas I, Benoit D, Chilingaryan G. Predictive validity of the Montreal Cognitive Assessment (MoCA) as a screening tool for on-road driving performance. Br J Occup Ther2015;78:100-108.

11. Papandonatos GD, Ott BR, Davis JD, Barco PP, Carr DB. Clinical utility of the Trail-Making test as a predictor of driving performance in older adults. J Am Geriatr Soc 2015;63:2358-2364.

12. Anstey KJ, Eramudugolla R, Chopra S, Price J, Wood JM. Assessment of driving safety in older adults with mild cognitive impairment J Alzheimers Dis 2017;57:1197-1205.

13. Hollis AM, Duncanson H, Kapust LR, Xi PM, O'Connor MG. Validity of the Mini-Mental State Examination and the Montreal Cognitive Assessment in the Prediction of Driving Test Outcome. J Am Geriatr Soc 2015;63:988-992.

14. Piersma D, Fuermaier A, de Waard D, De Deyn PP, Davidse RJ, de Groot J, et al. The MMSE should not be the sole indicator of fitness to drive in mild Alzheimer's dementia. Acta Neurol Belg 2018;118:637642 .

15. Han JW, Kim TH, Kwak KP, Kim K, Kim BJ, Kim SG, et al. Overview of the Korean longitudinal study on cognitive aging and dementia. Psychiatry Investig 2018;15:767-774.

16. Lee JH, Lee KU, Lee DY, Kim KW, Jhoo JH, Kim JH, et al. Development of the Korean version of the Consortium to Establish a Registry for Alzheimer's Disease Assessment Packet (CERAD-K) clinical and neuropsychological assessment batteries. J Gerontol B-Psychol 2002; 57:47-53.

17. Yoo SW, Kim YS, Noh JS, Oh KS, Kim CH, Namkoong K, et al. Validity of Korean version of the mini-international neuropsychiatric interview. Anxiety Mood 2006;2:50-55.

18. Tinetti ME. Performance-oriented assessment of mobility problems in elderly patients. J Am Geriatr Soc 1986;34:119-126.

19. Lee DY, Lee KU, Lee JH, Kim KW, Jhoo JH, Kim SY, et al. A normative study of the CERAD neuropsychological assessment battery in the Korean elderly. J Int Neuropsychol Soc 2004;10:72-81.

20. American Psychiatric Association. Diagnostic and Statistical Manual of Mental Disorders, Fourth Edition, Text Revision (4th Test Rev. Ed.). Washington, DC: American Psychiatric Association; 2000.

21. Winblad B, Palmer K, Kivipelto M, Jelic V, Fratiglioni L, Wahlund LO, et al. Mild cognitive impairment-beyond controversies, towards a consensus: report of the International Working Group on Mild Cognitive Impairment. J Intern Med 2004;256:240-246.
22. Iverson D, Gronseth G, Reger M, Classen S, Dubinsky R, Rizzo M. Practice parameter update: evaluation and management of driving risk in dementia: report of the Quality Standards Subcommittee of the American Academy of Neurology. Neurology 2010;74:1316-1324.

23. Matsuyama T, Kitamura T, Katayama Y, Hirose T, Kiguchi T, Sado J, et al. Motor vehicle accident mortality by elderly drivers in the super-aging era: a nationwide hospital-based registry in Japan. Medicine (Baltimore) 2018;97:e12350.

24. Korean National Police Agency. Annual Traffic Accident Data. 2018. Available at: http://kosis.kr/statisticsList/statisticsListIndex. do?menuId=M_01_01\&vwcd=MT_ZTITLE\&parmTabId=M_01_01 \&parentId=D2.1;132_13202.2;\#132_13202.2. Accessed August 15, 2019.

25. Ryan GA, Legge M, Rosman D. Age related changes in drivers' crash risk and crash type. Accid Anal Prev 1998;30:379-387.

26. Tefft B. American Driving Survey, 2015-2016. Washington, DC: AAA Foundation for Traffic Safety; 2018.

27. Korean Ministry of Land, Infrastructure and Transport. National Traffic Survey. Published 2013. Available at: https://www.ktdb.go.kr/www/ fileDownPblcte.do?pblcteNo=328. Accessed August 15, 2019.

28. United States Department of Transportation Federal Highway Administration. Average Annual Miles per Driver by Age Group. Published 2018. Available at: https://www.fhwa.dot.gov/ohim/onh00/bar8.htm. Accessed August 15, 2019.

29. Zhang G, Yau KK, Chen G. Risk factors associated with traffic violations and accident severity in China. Accid Anal Prev 2013;59:18-25.

30. Bennett JM, Chekaluk E, Batchelor J. Cognitive tests and determining fitness to drive in dementia: a systematic review. J Am Geriatr Soc 2016;64:1904-1917.

31. Crizzle AM, Classen S, Bédard M, Lanford D, Winter S. MMSE as a predictor of on-road driving performance in community dwelling older drivers. Accid Anal Prev 2012;49:287-292.

32. Grace J, Amick MM, D'abreu A, Festa EK, Heindel WC, Ott BR. Neuropsychological deficits associated with driving performance in Parkinson's and Alzheimer's disease. J Int Neuropsychol Soc 2005;11:766775.

33. Ross V, Jongen EM, Wang W, Brijs T, Brijs K, Ruiter RA, et al. Investigating the influence of working memory capacity when driving behavior is combined with cognitive load: an LCT study of young novice drivers. Accid Anal Prev 2014;62:377-387.

34. Hakamies-Blomqvist L, Siren A. Deconstructing a gender difference: driving cessation and personal driving history of older women. J Safety Res 2003;34:383-388.

35. Ralph ML, Powell J, Howard D, Whitworth A, Garrard P, Hodges J. Semantic memory is impaired in both dementia with Lewy bodies and dementia of Alzheimer's type: a comparative neuropsychological study and literature review. J Neurol Neurosurg Psychiatry 2001;70:149-156. 